\title{
Design of Rural Information Integrated Service Platform Based on Smart Phone
}

\author{
Zhang Li \\ College of information and management science \\ Henan Agricultural University \\ Zhengzhou, China \\ e-mail: Zhangli200312@eyou.com
}

\author{
Li Yan-ling \\ College of information and management science \\ Henan Agricultural University \\ Zhengzhou, China \\ e-mail: lyl_lingling@163.com
}

\begin{abstract}
With the development of the mobile Internet technology and the popularity of smart phones in rural areas, rural residents can get useful information and knowledge at any time by phone. For fast and easily accessing to information of relevant agricultural science and technology, this study will be talk about Web Services data mining technique combined with Android smartphone technology to collect the agricultural information in particular, and design and develop the rural information integrated service platform based on smart phones. In this way, foundation of query information release and search, such as On-line information browsing, network consulting, experts linking, plant diseases and insect pests, can be achieved to make mobile communication network and intelligent mobile phone to better serve the agricultural science and technology.
\end{abstract}

Key words- smart phone; rural information integrated service platform; Android; agricultural information push; agricultural warning

\section{INTRODUCTION}

With the development of the market economy, the farmers increasingly demand for information, such as agricultural production and agricultural product supply. But in the rural economy is relatively backward, and most farmers knowledge level is limited, using computer and broadband network and the condition of agriculture information sharing are limited. In addition, the way of accessing to information is single, and cannot satisfy various requirements. Meanwhile, computers and networks expensive cost and quality requirements for the operator, it will be cut off most of the farmers in the network information. At the same time, smart phone which has advantages, such as, low price, simple and convenient operation is gradually popular. Smart phone configuration is higher, and function is rich, such as integrating telephone, entertainment, office, even catching up PC performance processor. The price is lower, And gradually reach more and more widely. Because the mobile phone is portable, as well as in the fields by mobile Internet access wireless network is easier. Rural information service provides a new means of information transmission, Provide strong support for the innovation of rural information service [1]. With smart phone continued rapid growth in rural area and farmers on the spread of information recognition rate, the rise of the related software and services based on mobile phone and the launch of the lag, therefore, to develop the corresponding application software and provide the relevant mobile service is particularly urgent. This study aimed at the status quo, on the Android smart phone platform to develop a can run on the smart phone agricultural information and information systems will be convenient for farmers, at the same time can greatly improve the agricultural information construction; promote the rapid development of Rural economy [2].

\section{SYSTEM DESIGN}

\section{A. System general structure}

Rural information integrated service platform based on smart phone with reference to the MVC design pattern, in which the View to show the user Model of state and control information, the Controller as the Controller, responsible for process control between the View and Model. Used by the application layer, support layer, data layer consisting of three-layer client/server structure system, to improve system can expandability, maintainability, portability, easy to software engineering management. System general structure is shown in Fig .1. 
dynamic, laws and regulations, including the agricultural pictures, etc., using the client to the domain experts such

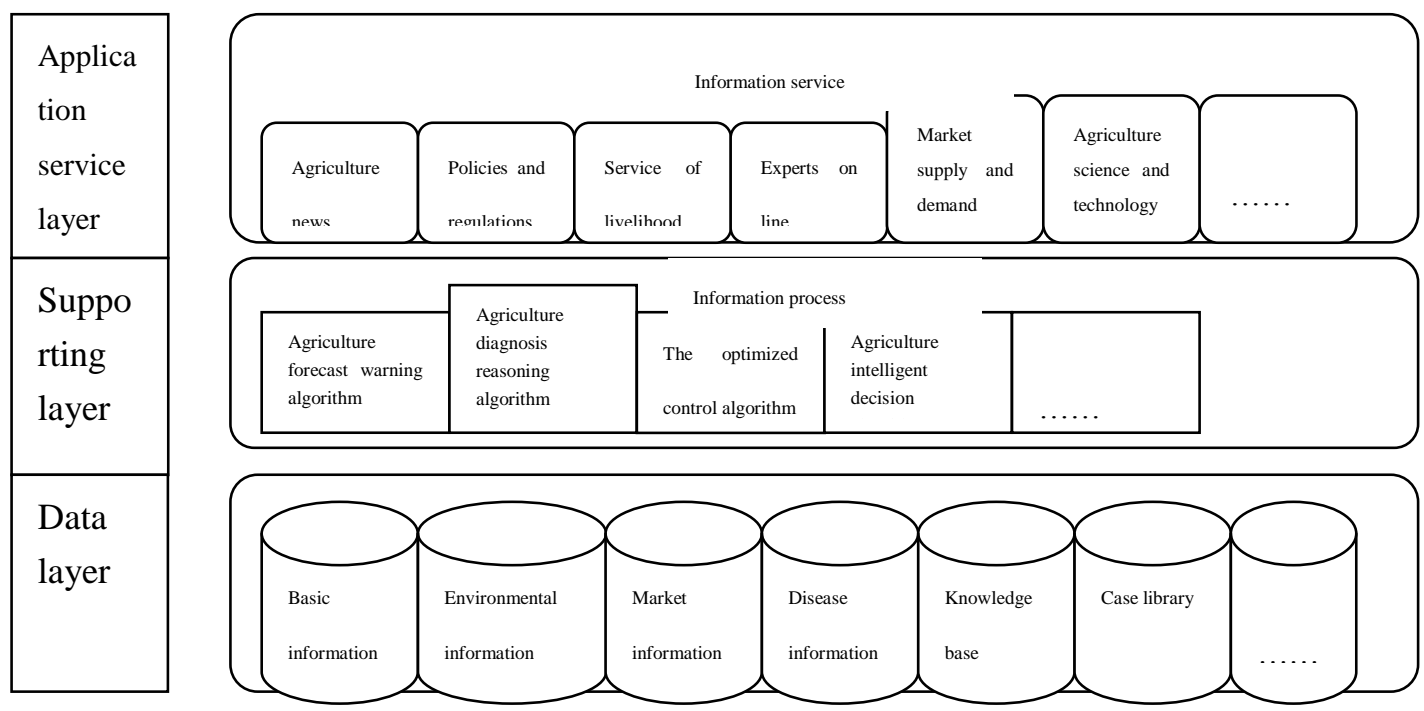

Figure 1. System General Structure practical technologyinformation,

market information, etc. Online consultingfunction is users adopt the mode of text,

1) Data layer: Mainly includes plant diseases and insect pests of agricultural technology information database, agricultural expert information database, database and remote education information database, etc., for the application layer provides a rich source of data.

2) Support layer: The system of the business logic layer is a rural information integrator service platform client, based on the data layer, depending on the type of database, using JDBC (Java database connectivity, Java database connectivity), ODBC (open database connectivity, open database connectivity) or XMLAPI and database connection is established [3].

3) Applycation layer: Presentation layer mobile terminal by running the client sends a request, and parse and display server feedback information; But also by the client browser to access the website, browse and view specific information. According to the rural information service demand of positioning, mainly for the broad masses of farmers and agricultural workers at the grass-roots level, large farming and agricultural scientific research workers etc.

\section{B. system function design}

Based on the Android platform of rural information integrator service platform is mainly composed of mobile client, web sites and background management of 3 modules.

1) Mobile client modules: Main realization information browsing, online consulting, experts online, knowledge retrieval and online service of supply and demand, and other functions. The information browsing is the user by the client to check the relevant column information, as questions or plant diseases and insect pests in agricultural production, livestock farming and epidemic prevention. Online functions are agricultural experts detailed information entry system users can directly from the client by calling the experts, saves on the information query relevant experts. Knowledge retrieval function refers to the use of plant diseases and insect pests of knowledge retrieval database client software, easy to operation. The service function of supply and demand, provide users with a simple electronic business function, can use the client to release or query of means of agricultural production, agricultural products and other market information.

2) Web site module: mainly based on fixed Internet service for the user, the user can use mobile phone login Web site query information announcement, etc. The remote education function refers to the user can use the cell phone into the system home page to watch about agricultural production, rural health, rural education and relevant education video. The service function of supply and demand is refers to the user can also use the website released agricultural production data information, etc. Consulting disambiguation is the website version of the online consulting function, using the web site related consulting experts and wait for the reply, expert users is to view the latest information and reply.

3) Background management module: Mainly for the administrator to provide user management, information management, and other functions. User management function is mainly for ordinary users and expert users registered information maintenance and management. Information management function is the administrator to release relevant announcements, or to experts released information release or return after checking accordingly. Consulting processing functions is the maintenance of the proposed consulting information by administrator (expert replies, recommend operation, etc). The processing 
function of supply and demand is the administrator of the needs of the user's information authenticity identification, delete false or inaccurate information.

\section{C. the client data model}

In mobile client, for Android applications to use SQLite database, database table design is shown in table 1.

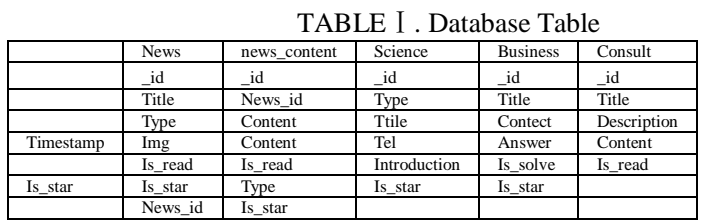

\section{SYSTEM IMPLEMENTATION}

In the process of implementation, the use of mobile client Java Development system, Web sites and background management system, select the Android Development Tools for the Development of simulation Tools, the client use SQLite as the database system, database using MySQL server. System development and implementation under the environment of the Eclipse. System USES hardware environment is mainly the Android smartphone, first set up the Android SDK + Java JDK6 has + the Eclipse development environment, development based on the Android version. With Apache Tomcat 6.0 for system server, use the JSP + Servlet + JavaBean technology model for the design and implementation of each module [4].

\section{THE FUNCTION OF THE THE PLATFORM}

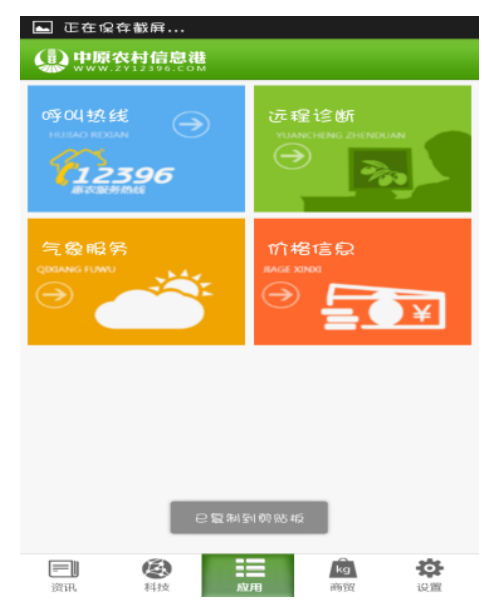

Figure 2. System Running Interface

\section{A. query of agricultural information}

Using smart phone as agricultural information inquiry of the client, in view of the present in the low level of agricultural population common agricultural information, agricultural information query module provides all kinds of humanized human-computer interface, including messages, texts, voices, pictures and videos, by touching the screen or according to the prompt can complete the information query.

Establishing agricultural ontology database on the server database, agricultural technology, geographic information database, database, the database of supply and demand of agricultural products, agricultural prices agricultural meteorological database and agricultural disasters database, agricultural producers can according to need to carry on the corresponding query, also can undertake cross-database compound queries, and even mobile phone GPS system for passive database query, namely the phone's own geographic information sent to the service platform, the platform to push corresponding location information to farmers.

\section{B. crop remote diagnosis}

Agricultural producers through smart phones client program to crop disease images characteristics of early comparison, if you can match is successful, the confirmation can offer diagnosis treatment scheme by the server. If not in the plant diseases and insect pests of database matching, then select the remote register, make an appointment to corresponding crops category of experts, the program automatically start camera, microphone and positioning system, crop information acquisition program up and running, the image and the geographic information sent to the remote server, and to establish a session channel between producers and experts, the expert can communicate and agricultural producers, auxiliary for judgment, then the solution is given.

\section{C. disaster warning}

Disaster warning mainly divided into plant diseases and insect pests of early warning and meteorological disaster early warning, and through the analysis of the meteorological information system warning, plant diseases and insect pests of mathematical model with the traditional information release platform is the biggest difference between the content of the early warning information and send the target region targeted, greatly saves the cost data use [5].

\section{D. personalized knowledge push service}

Agricultural information push service is the needs of different groups within the territory of a pointer to the agricultural development of personalized information push service, because of its convenient, quick, practical, save money, and many other advantages, more and more get the welcome of farmers. Users can through the way of text messaging on mobile phones free access to or consulting related issue of agriculture [6], including agricultural science and technology information, market information, price information, supply and demand information, technical solutions, policies and regulations, life common sense, such as information, message content involves cultivation, the fruit trees, vegetables, animal husbandry, agricultural products processing and other aspects. Information provided by the rural information integrated service platform. Text messages from various areas in the province of agriculture experts carefully selected, analysis, processing, by the site management personnel into different text, through the platform phones, sent to the farmers meet the personalized needs of farmers $[7,8]$. 


\section{E. public opinion survey}

Urgent problems surrounding rural industry development, rural family life and requirements, and all kinds of subsidies, the villages and towns work Suggestions, etc., design the questionnaire. Use of network platform, targeted to carry out the rural community social situation investigation, for all levels of government to listen to their opinions, and community and public opinion, gather intelligence to provide important channels [9].

\section{CONCLUSION AND DISCUSSION}

The distinctive features of the platform has the following several aspects: 1) authoritative, accurate, timely information, strong pertinence, practicability and effectiveness;2) the platform after the government departments, units of agricultural scientific research to promote, leading enterprises and agriculture experts powerful team support, and can provide normalized agricultural information services;3) with large database technology and powerful search function, can solve most of the online technology problems;4) through a telephone hotline to provide professional and personalized service in agricultural technology.

This system on the basis of powerful mobile networks, on the smartphone platform to realize the development of agricultural information service system, make the broad masses of farmers to easily get the latest information on agricultural science and technology, to strengthen agricultural information service, improve farmers' quality of science and technology; Therefore, the use of mobile intelligent terminal for rural information service has a unique advantage [10].

The agricultural information integrator service platform based on smart phone will further promote the development of agricultural informatization. For our province agricultural income growth, the improvement of agricultural competitiveness and the socialism new rural construction provides a new thrust, in helping farmers across the digital divide, speed up agricultural modernization, promoting the rural economy structure adjustment and so on has important strategic significance.

\section{ACKNOWLEDGMENT}

This work was supported partially by Henan Province Major Science-technology Project under Grant No.131100110400, and Science-technology Research Project of Zhengzhou city under Grant No.141PPTGG43 1 .

\section{REFERENCES}

[1] Fang Fan,Ma Youhua,Ding Wenjin,Fang Xinglong,Wang Qiang, "The Progress of the Application of Mobile GIS in Modern Agriculture,"Journal of Agriculture, Vol.4, No.5, 2014,pp.86-89.

[2] FANG Yu,HUANG Liang,CHEN Shi-ping, "Operation Mode and Development Prospects of Agricultural Information Service Platform Based on Android System,"Rural Economics, Vol.19,2014,pp.340-341.

[3] GAO Kai, "Android intelligent mobile phone application development tutorial,” National Defence Industry Press,2012

[4] LIU Fu-ying,LIU Yan, “Android Mobile Progrmmming Practical Giude,’Bei Jing:Electronic Industry Press,2011.

[5] LI Dao-liang,PU Ze-tian,WEN Ji-wen,DUAN Qing-ling, "The Remote Diagnosis and Early Warning Technologies for Agriculture Disease an Insect," Bei Jing:TSINGHUA UNIVERSITY PRESS, 2010.

[6] ZHANG Chang-xue,ZHANG Wei,DONG Zhi-ming, “Aspects of mobile Push Technology,"Mobile Communications, Vol.35, No.5,2011, pp.21-27.

[7] ZHOU Hong,ZHANG Bei,JIANG Ai-rong,et al. "Design and Implementation of Library Bibliography Information Self SMS Push Service,"New Technology of Library and Information Service, Vol (7-8),2011,pp.127-131.

[8] NI Hong-jun, "Research and Implementation of Message Push Based on Android," RESERCH AND EXPLORORATION IN LABORATORY, Vol.33, No.5,May 2014,pp.96-100.

[9] MENG Xiang-Wu,HU Xun,WANG Li-Cai,ZHANG Yu-Jie, "Mobile Recommender Systems and Their Applications,"Journal of Software,Vol.24, No.1, January 2013,pp.91-108.

[10] ZHANG Hai-feng, "Prospect of Application of Agricultual Information Service Platform Based on Android Intelligent Mobile Phone,"Heilongjiang Agricultural Scinces,Vol.8,2014,pp.126-127. 